\title{
Industrial Tests of Current Distribution Dynamics in the Brush-contact Apparatus of the Turbo-generator
}

\author{
Igor Plokhov, Igor Savraev, Alexander Markov, Alexander Ilyin, \\ Oksana Kozyreva, Nikita Kotkov \\ Pskov State University, Department of Electric Drive and Automation Systems. \\ Address: Lenina 8, Pskov, 180000, Russia.
}

\begin{abstract}
The article is devoted to analysis of the results of industrial tests of current distribution dynamics in the brush-contact apparatus of the turbo-generator TVV-800 (800 MW) using a microprocessor based monitoring system. New methods of assessing the quality of current-collecting devices functioning is developed, allowing to assess current transfer in dynamics and to determine their quality characteristics. New trends of current distribution dynamics between the parallel brushes that allow on the basis of statistical and variance analysis to develop practical recommendations for maintenance of these devices are revealed. The results of the research in the form of scientific articles are published for the first time.
\end{abstract}

Keywords: industrial tests, turbo-generator, brush-contact, current distribution between the parallel brushes.

\section{INTRODUCTION}

The electrical sliding contact is one of the main technical devices intended to transfer current between stationary and moving parts of electrical machinery and apparatus. The transmission of electrical current through sliding contact is accompanied by heating of the contacting parts, sparking and arcing [1, 2]. Mechanical vibration of parallel sliding contacts and the wear lead to the unbalanced distribution of current between the contacts (brushes), overcurrents and thermal overloads and result to decreasing the reliability of the brush-contact device (BCD). The electromagnetic instability of BCD leading to "ring fire" on the contact rings can occur [3, 4]. Methods and devices for monitoring physical characteristics of BCD [5-8] and for measurement of currents of the individual brushes are known [9, 10].

Powerful turbo-generators have BCD for supplying current to the rotor windings. Individual brushes and brush groups established in removable cassettes pressure on the slip ring is necessary to regulate in operation of $\mathrm{BCD}$. Otherwise after a while there is a significant overload of some brushes and no-load condition of the others. It leads to increased wear of the brushes, overheating and damage of the contact pairs and entire cassette. Now current measurement of the separate brushes and brush groups is performed using portable operative diagnostics devices that enable to measure currents brushes separately, but they are not able to show instantaneous distribution of the currents in all brushes $[9,10]$. It should noted that BCD of the turbo-generator TVV-800 has 100 brushes, so tuning the device for even current load is very labour and time consuming task.

New method of current distribution monitoring in $\mathrm{BCD}$ of the electric machine and the device for its implementation as a microprocessor system have been applied and patented by the team of the authors [11].

\section{MATERIALS AND METHODS}

The next indicators were used to determine the quality of the current distribution in turbo-generator $\mathrm{BCD}$ - representing the time dependence of the average deviation currents brush cassettes $q_{j}, \%$ and the standard deviation of currents brush cassettes $Q_{j}, \%$ from the average current of brush cassette $I_{a v j}$ for a given period of time:

$$
\begin{gathered}
q_{j}=100 \cdot \sum_{i=1}^{N}\left|I_{i j}-I_{a v j}\right| /\left(N \cdot I_{a v j}\right), \\
Q_{j}=\frac{100}{I_{a v j}} \cdot \sqrt{\sum_{i=1}^{N} \frac{\left(I_{i j}-I_{a v j}\right)^{2}}{N}}, \\
I_{a v j}=\frac{1}{N} \sum_{i=1}^{N} I_{i j}
\end{gathered}
$$

where $I_{i j}$ - the current of the cassette № $\mathrm{j}$ in the measurement № i, $\mathrm{j}=\mathrm{i}$...k; $I_{a v j}$ - average current of all cassettes for a given period of time, $\mathrm{N}$ is the number of measurements. 
Then $q, \%$ are the time dependences of the average deviation of the currents of the brush cassettes from the average current of the cassettes for a given period of time and $Q, \%$ - time dependences of the standard deviation of the cassette currents from the average current of the cassettes for a given period of time.

We using a microprocessor monitoring system recorded digitally the current distribution on the brush cassettes (in each cassette there are 5 brushes) and the on-line setting of BCD for even current load of the brush cassettes. In the operation of the system at the Nizhnevartovsk State District Power Stations a significant amount of experimental data have been accumulated and processed by means of which the dynamics of current distribution of cassette of brushes has been analyzed and a number of previously unknown physical laws of functioning of the current device with sliding contacts of large turbo-generator have been revealed. New methods of analysis of the obtained results was developed. Program for statistical processing of measurements and for creation of graphs which allows to build the schedule was created:

1) graphs of the current of cassette № $i I_{i}$ for the measurement time;

2) graphs of the current of pole of BCD for a specified period of time

$$
\begin{aligned}
& I_{g}=\sum_{i=N_{g}+1}^{N_{g}} I_{i}, \\
& I_{e}=\sum_{i=N_{g}+1}^{N_{e}} I_{i},
\end{aligned}
$$

where $\mathrm{N}_{\mathrm{g}}$,- the number of cassettes of poles of BCD $(\mathrm{G}$ - side «Generator») on a ring with positive polarity, $\mathrm{N}_{\mathrm{e}}$ - the number of cassettes of poles of $\mathrm{BCD}$ (side «Exciter») on a ring with negative polarity; 3) indicators of the quality of the current distribution $q_{j}$ and $Q_{j}$ in time.

The program also allows to display the new dynamic characteristics, developed by the authors:

- the locus diagram of a unbalance of current load of the sides of the pole of BCD

$$
f_{g g}\left(I_{g a}, I_{g \sigma}, t\right), f_{g e}\left(I_{e a}, I_{e \sigma}, t\right)
$$

where $I_{g a}$ is the current of the pole from the side «Generator» (side «A»), $I_{g b}$ is the current of the pole from the side «Generator» ( side $« \mathrm{~B} »), I_{e a}$ is the current of the pole from the side «Exciter» (side «A»), $\mathrm{I}_{e b}$ is the current of the pole from the side «Exciter» $($ side $« \mathrm{~B} ») ; \mathrm{T}$ - time;

- the dependence of the relative systematic measurement error from time $(\varepsilon-$ for excitation current of BCD, $\varepsilon_{j}-$ for the current $\mathrm{j}$ cassettes), where $\mathrm{N}$ is the number of cassettes of one pole, $\mathrm{N}_{\mathrm{g}}-$ the maximum number of cassettes of the pole "Generator"; $\mathrm{N}_{\mathrm{e}}$ - the maximum number of cassettes of the pole "Exciter"

$$
\begin{array}{r}
\mathrm{E}_{j}=100 \cdot \frac{\sum_{i=1}^{N_{2}} I_{i j}-\sum_{i=N_{2}+1}^{N_{6}} I_{i j}}{\sum_{i=1}^{N_{2}} I_{i j}+\sum_{i=N_{2}+1}^{N_{6}} I_{i j}} \\
\varepsilon_{j}=\left(\sum_{i=1}^{N_{2}} I_{i j}-\sum_{i=N_{2}+1}^{N_{B}} I_{i j}\right) / I_{j} / N
\end{array}
$$

- a time dependence of the imbalance of the measured values of the total currents of poles.

- the locus diagram of a equilibrium of the currents system of the pole of BCD

$$
f_{e g}\left(x_{o g}, y_{o g}, t\right), f_{e e}\left(x_{o e}, y_{o e}, t\right)
$$

For getting generalized information about the dynamics of the current transfer in group sliding contact of a separate pole will introduce the concept of a hodograph of an equilibrium of current system as a function of the center mass coordinates of a regular polygon with weight coefficients of the vertices equal to the brush cassette currents. The axial projection of the BCD pole is shown schematically for the explanation in Fig. 1.

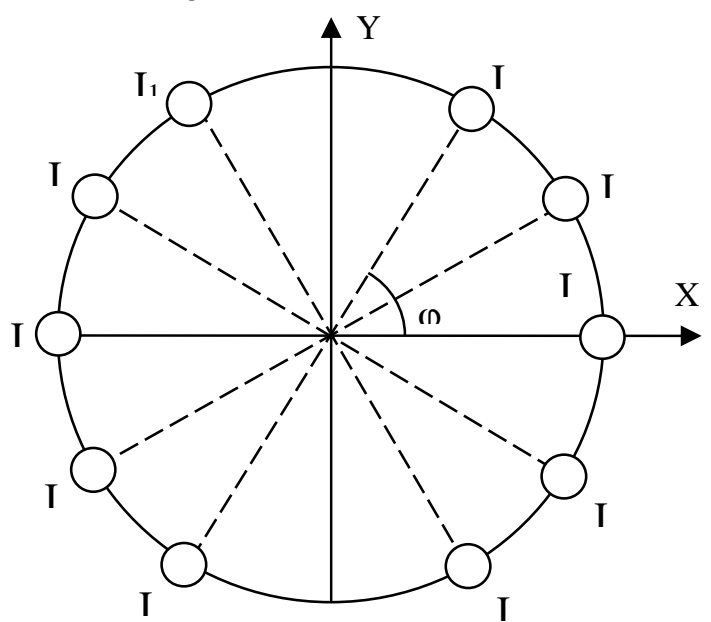

Fig. 1. To the construction of the hodograph of the equilibrium of the currents.

Each pole has two groups of brushes "series A" and "series B" placed on different sides of BCD. Redistribution of the currents there are between rows and between individual brackets $\left(\mathrm{I}_{\mathrm{A}} \neq \mathrm{I}_{\mathrm{B}}\right)$ given that $I_{\text {exc }}=I_{A}+I_{B}$. An excessive current of the load affects the quality of functioning of BCD causing overheating of brushes, increasing the sparking and the wear. We define the numeric indicators determining the deviation of the excitation current of the nominal value and the degree of uneven loading of the row of brushes.

The instantaneous position of the point of the equilibrium defined as: 
Environment. Technology. Resources, Rezekne, Latvia Proceedings of the $11^{\text {th }}$ International Scientific and Practical Conference. Volume III, 258-268

$$
\begin{array}{r}
X_{0}(t)=\frac{\sum_{i=1}^{N} I_{i}(t) \cdot \cos \left(\varphi_{i}\right)}{\sum_{i=1}^{N} I_{i}(t)}, \\
Y_{0}(t)=\frac{\sum_{i=1}^{N} I_{i}(t) \cdot \sin \left(\varphi_{i}\right)}{\sum_{i=1}^{N} I_{i}(t)}
\end{array}
$$

and the statistically average equilibrium coordinates as the integral estimation of the mathematical expectation:

$$
\begin{gathered}
X_{0}=\frac{1}{T} \cdot \int_{0}^{T} X_{0}(t) d t, \\
Y_{0}=\frac{1}{T} \cdot \int_{0}^{T} Y_{0}(t) d t,
\end{gathered}
$$

where $\mathrm{T}$ - total measurement time.

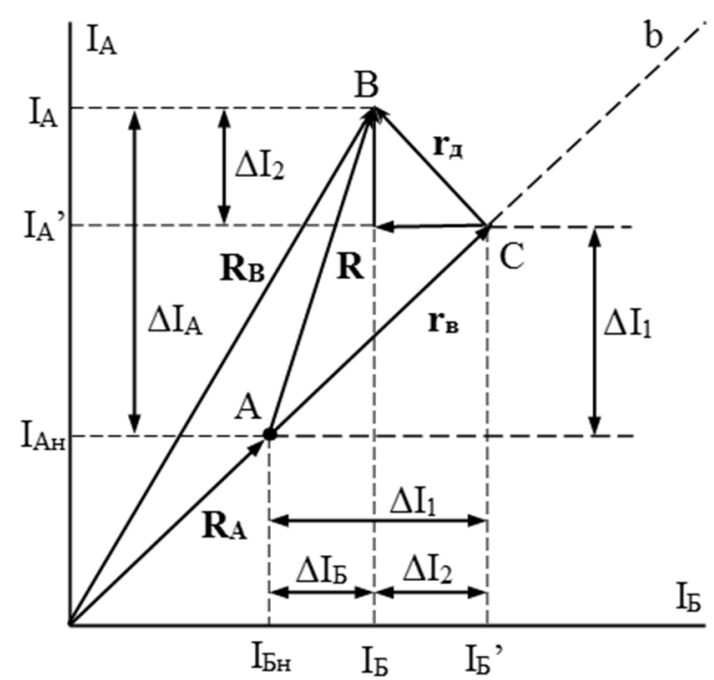

Fig. 2. To the definition the indicator of imbalance of series.

The point of the nominal mode in the absence of non-uniform loading of the rows - point $A=\left(I_{A n}, I_{B n}\right)$ with $\mathrm{I}_{\mathrm{An}}=\mathrm{I}_{\mathrm{Bn}}$ and a point corresponding to the nonideal operation mode of $B C D\left(I_{A} \neq I_{B}\right)$ shows in the vector diagram (Fig. 2). The position of the operating points is characterized by the vectors $R_{A}$ and $R_{B}$. The deviation of the operating point from the nominal position specifies the vector $\mathrm{R}$, which is represented by the sum of the vectors $r_{d}$ and $r_{b}$, defining the deviation of the excitation current of the nominal value and the uneven loading of series (vector of imbalance).

From the vector diagram it follows:

$$
\begin{gathered}
\Delta I_{1}=\Delta I_{B}+\Delta I_{2}, \Delta I_{2}=\left(\Delta I_{A}-\Delta I_{B}\right) / 2, \\
\Delta I_{1}=\left(\Delta I_{A}+\Delta I_{B}\right) / 2,
\end{gathered}
$$

where $\Delta \mathrm{I}_{1}$ is the scalar index of the deviation of the excitation current from the nominal value; $\Delta \mathrm{I}_{1}$ is the indicator of the imbalance of series. Moreover $\Delta \mathrm{I}_{\mathrm{A}}$ $\Delta \mathrm{I}_{\mathrm{B}}$ are determined using the known values currents of series $I_{A}$ and $I_{B}$ and using the nominal value currents:

$$
I_{A n}=I_{B n}=I_{e x c} / 2 .
$$

That is

$$
\Delta I_{B}=I_{B}-I_{B_{n}}, \Delta I_{A}=I_{A}-I_{A_{n}} .
$$

BCD of the turbo-generator TVV-800 contains 100 brushes placed in 20 removable brush cassettes: 10 cassettes for each pole. The numeration of the cassettes starts from the pole "Generator" which located closer to the turbo-generator and continues to the pole "Exciter" which located closer to the exciter. Cassette of pole are divided into the series of " $A$ " and into the series of " $\mathrm{B}$ " located on different sides of BCD under protective covers. Every series has 5 cassette on the pole (Fig.3).

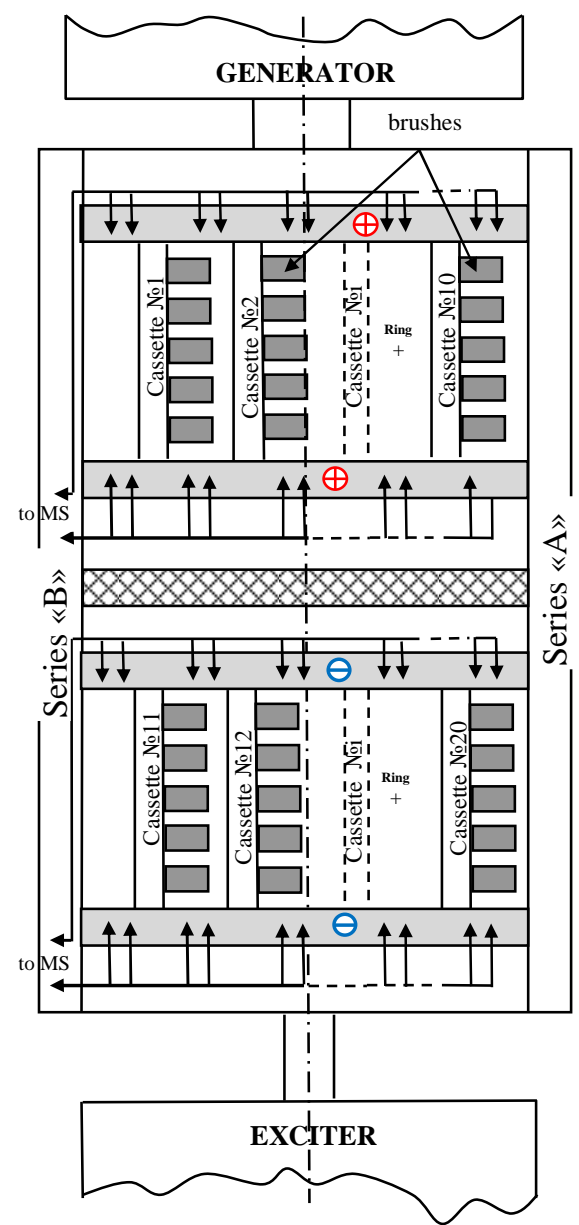

Fig.3. The brush-contact device of the turbo-generator.

The main blocks of the monitoring system MS and the placement on the case of BCD shown in Fig. 
4.The operation principle of the system is to measure the voltage drops on the current-carrying portions of the brush traverses with the following calculation by derived formulas the currents of the brush cassette (Fig.5) [11, 12]:

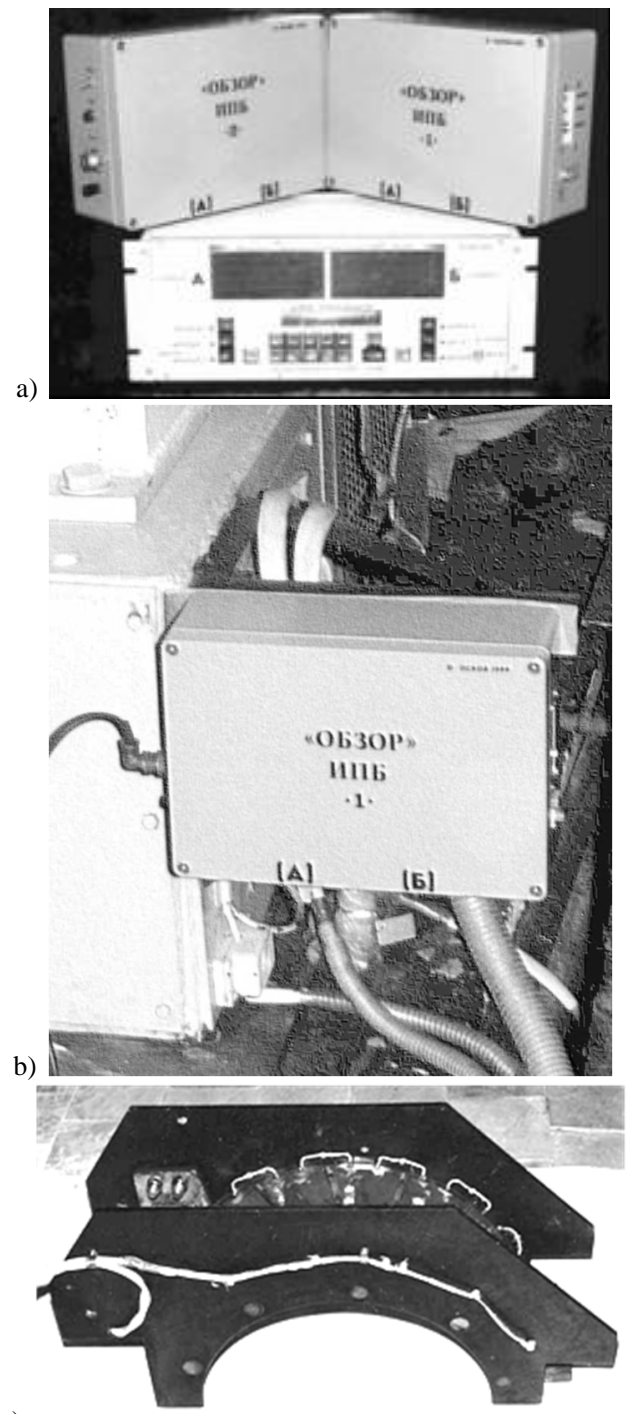

c)

Fig. 4. Blocks of the monitoring system (including a block of visual output of information about the measured currents of the cassettes) (a); measuring-transducer block in the case of BCD (b); section of the case of BCD TVV-800 with signal cables of diagnostic system (c).

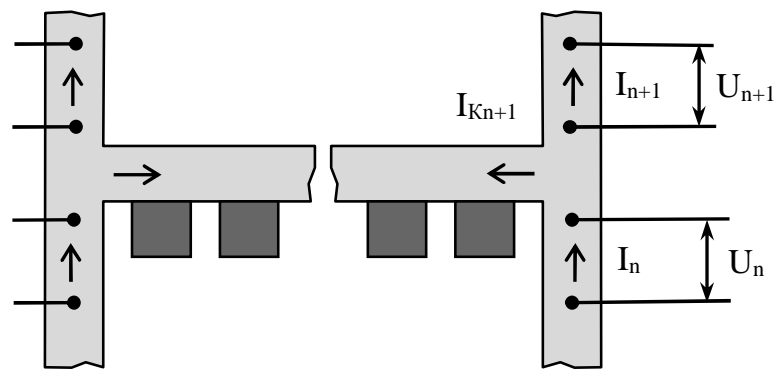

Fig.5. To determine the current of the cassette.
The current of the cassette is determined by the formula:

$$
I_{K n+1}=I_{n+1}-I_{n}=\left(U_{n+1}-U_{n}\right) \times G,
$$

where $U_{n+1}$ and $U_{n}$ are measured drops in voltage in the same part of the current bus of the pole;

$\mathrm{G}$ - the conductivity of the relevant part.

The calculated values of the cassette currents can be displayed visually in relative units, or calculated in absolute units according to the current consumption of the current bus.

\section{RESULTS AND DISCUSSION}

Graphs of the some cassettes currents of BCD measured by the system over a period of 900 hours and with an interval of 0.5 hours with the placed over linear approximation are shown in Fig. 6 and Fig. 7. Cassettes with the most unstable current distribution in time were selected.
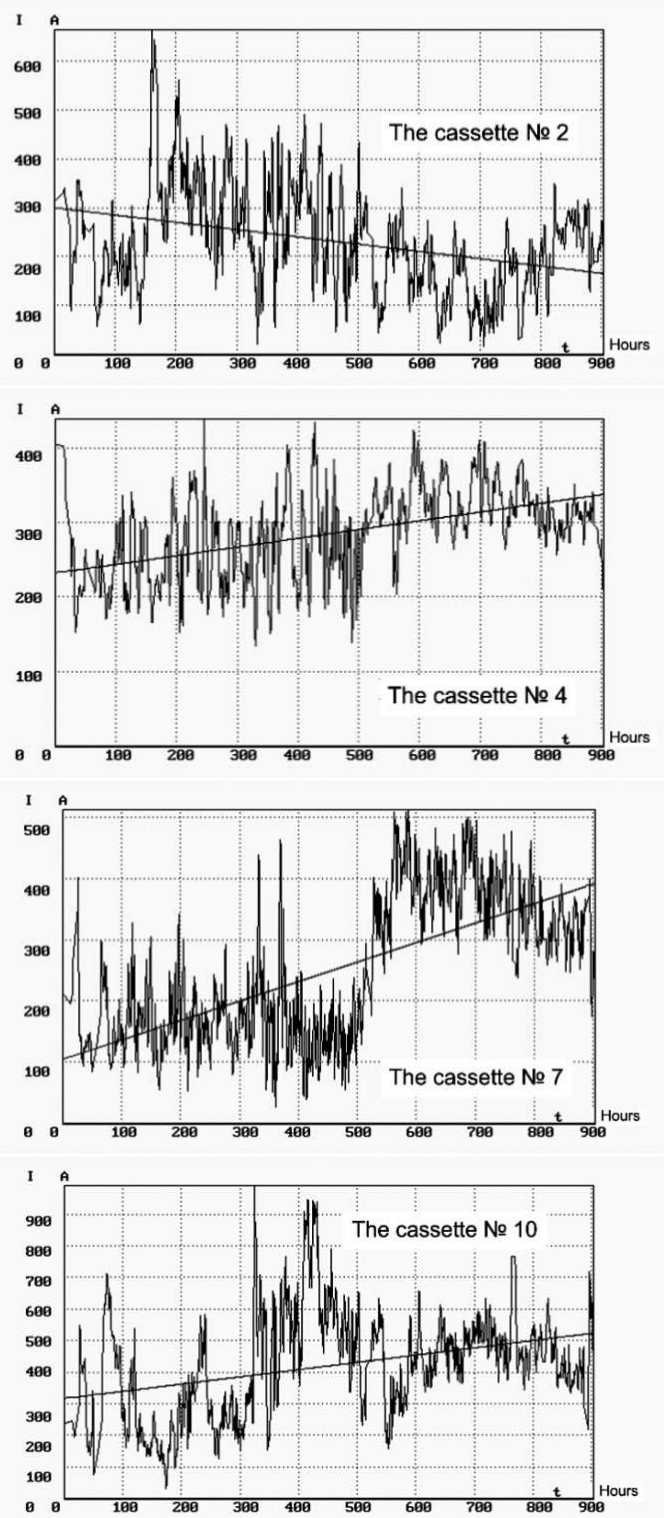

Fig. 6. The currents of the brush cassette of the pole "Generator" (straight line is linear approximation of the obtained graph) 
The assessment of presented graphs allows us to make the preliminary estimations and conclusions:

- the process of a drift of load current of the brush of the cassettes are stochastic in nature;

- most of the graphs contains the 0.5-2 hours intervals during which the current exceeds the average value more than two times;

- there are periods during which the separate cassette are practically deenergized.

The graphs of the pole "Generator" cassettes currents are more chaotic. It can be explained by the fact that in the test period the ring had the higher level of the wear and vibration.
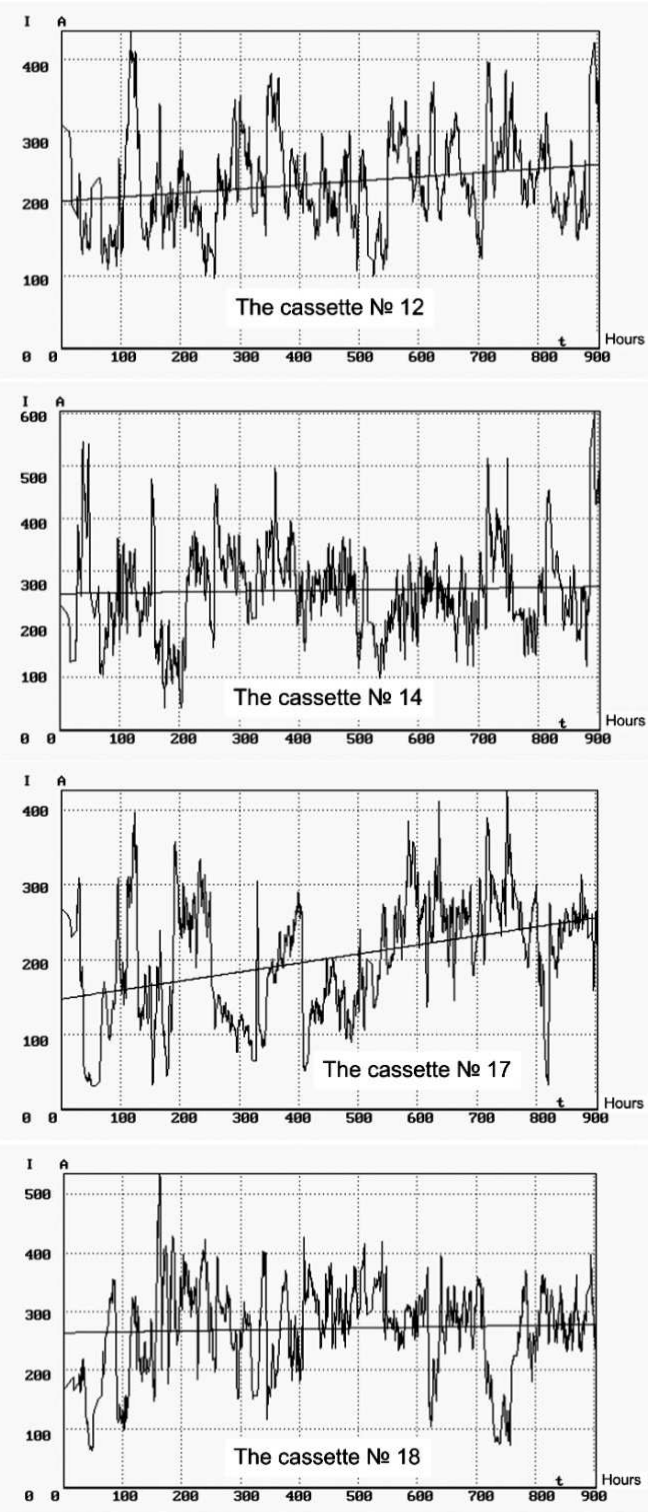

Fig. 7. The currents of the brush cassette of the pole "Exciter" (straight line is linear approximation of the obtained graph).

The linear approximation of the graphs allows to conclude that the average currents of the cassettes are in the range 200-300 A (40-60 A for one brush, in this case the nominal current of the brush is $80 \mathrm{~A}$ ).
Comparison of the integral indicators of individual brushes cassette and pole of BCD their current load for the study period and the stability of current transfer is given in Table 1 .

Table 1.

\begin{tabular}{|c|c|c|c|c|c|}
\hline 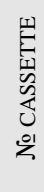 & 壱 & 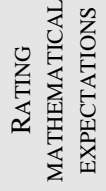 & 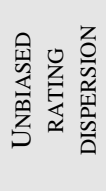 & 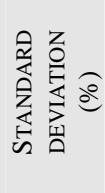 & 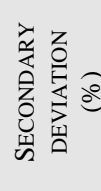 \\
\hline 1 & 1726 & 292 & 16199 & 43.4 & 33.2 \\
\hline 2 & 1726 & 230 & 15082 & 53.2 & 41.5 \\
\hline 3 & 1726 & 324 & 15941 & 38.8 & 29.8 \\
\hline 4 & 1726 & 286 & 5962 & 26.9 & 21.3 \\
\hline 5 & 1726 & 284 & 9345 & 34.0 & 25.3 \\
\hline 6 & 1726 & 342 & 12436 & 32.5 & 24.7 \\
\hline 7 & 1726 & 252 & 17924 & 52.9 & 45.5 \\
\hline 8 & 1726 & 219 & 7390 & 39.2 & 30.0 \\
\hline 9 & 1726 & 249 & 15233 & 49.4 & 39.3 \\
\hline 10 & 1726 & 423 & 33972 & 43.5 & 34.3 \\
\hline 11 & 1726 & 238 & 6227 & 33.1 & 26.4 \\
\hline 12 & 1726 & 229 & 4849 & 30.3 & 24.1 \\
\hline 13 & 1726 & 190 & 3986 & 33.2 & 24.9 \\
\hline 14 & 1726 & 264 & 9274 & 36.4 & 28.1 \\
\hline 15 & 1726 & 311 & 17118 & 42.0 & 36.9 \\
\hline 16 & 1726 & 166 & 7305 & 51.4 & 41.6 \\
\hline 17 & 1726 & 203 & 6954 & 40.9 & 33.9 \\
\hline 18 & 1726 & 270 & 7303 & 31.5 & 24.7 \\
\hline 19 & 1726 & 201 & 9836 & 49.3 & 40.3 \\
\hline 20 & 1726 & 285 & 4470 & 23.3 & 17.8 \\
\hline
\end{tabular}

The average values indicators for the poles are:

- the dispersion: 14948 - pole "G", 7732 - pole "E";

- the standard deviation: 41.4 - pole "G", 36.1 pole "E";

-the average deviation: 36.1 - pole "G", 29.8 pole "E".

Used assessment leads to the conclusion, that the pole "Generator" works almost twice less stable than the pole "Exciter".

Let's plot the currents of brush cassettes in a form of histograms, where each column corresponds to the current of a certain cassette in a given time. The histograms of currents during four hours work of BCD captured at intervals of 1 hour from $t=300$ hours and up to the beginning of continuous measurements are shown in Fig. 8.

The numbers of cassettes is on the $\mathrm{x}$-axis and the value of current consumed in a given moment of time is on the y-axis.

The currents of the pole "E" change noticeably slower than the currents of the pole "G", that is also confirmed by study of the graphs of the first derivative of current in dynamic processes that are represented selectively in Fig. 9. 

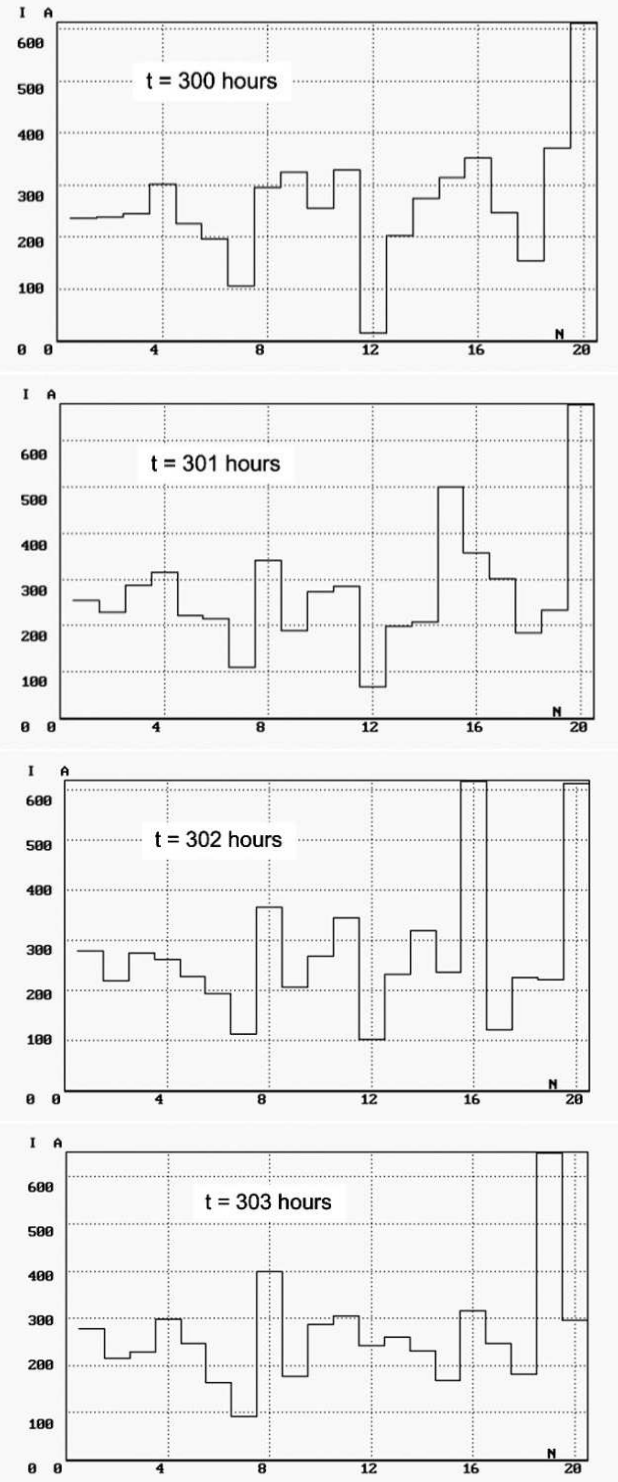

Fig. 8. The histogram of the current distribution in the cassettes of $\mathrm{BCD}$ in fixed moments of time $\mathrm{t}(\mathrm{N}$ is the number of the cassette).

For cassettes № 1, № 2 of the pole "G" the rate of current change is 100-150 A/hour, and for cassettes № 11, 12 of the pole "E" - no more than 30-50 A/hour, that allows to conclude about more highquality work of the pole "E" of BCD. A polishing of the ring contact surface located on the generator side is recommended to agree the described research results.

Let's consider the graphs of changing poles currents calculated as the sum of the individual cassettes currents (Fig. 10). The currents are in the range of 2000-3000 A. There are daily deviations of the excitation current that do not exceed $20 \%$ and there are also daily deviations of the shorter duration that do not exceed $10 \%$.
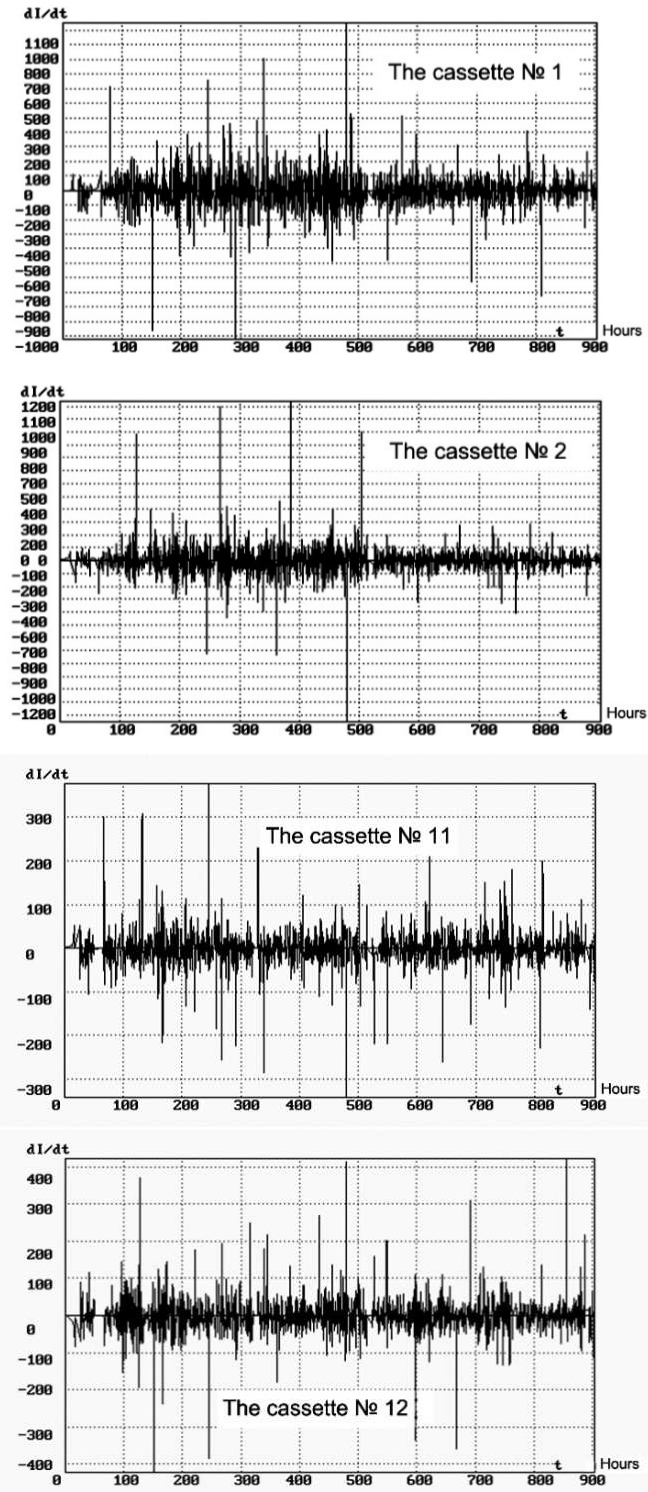

Fig. 9. The rate of a change of the current some cassettes of the different poles BCD.
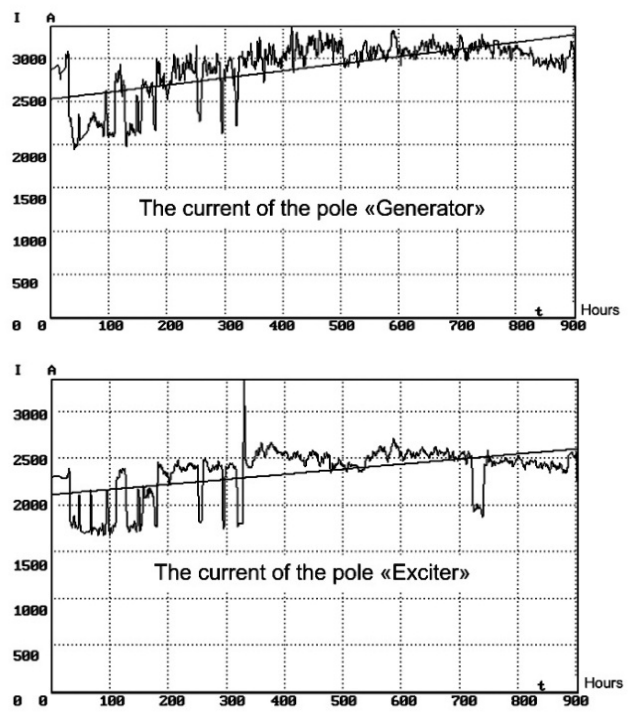

Fig. 10. Graphs of the change of currents of the poles of BCD for 900 hours of work (straight line is linear approximation of the obtained graph). 
The graphs of the first derivative of the currents of the poles (Fig. 11) allow to make conclusion about the stability of the current transfer through total sliding contact brush cassettes of the corresponding BCD poles.
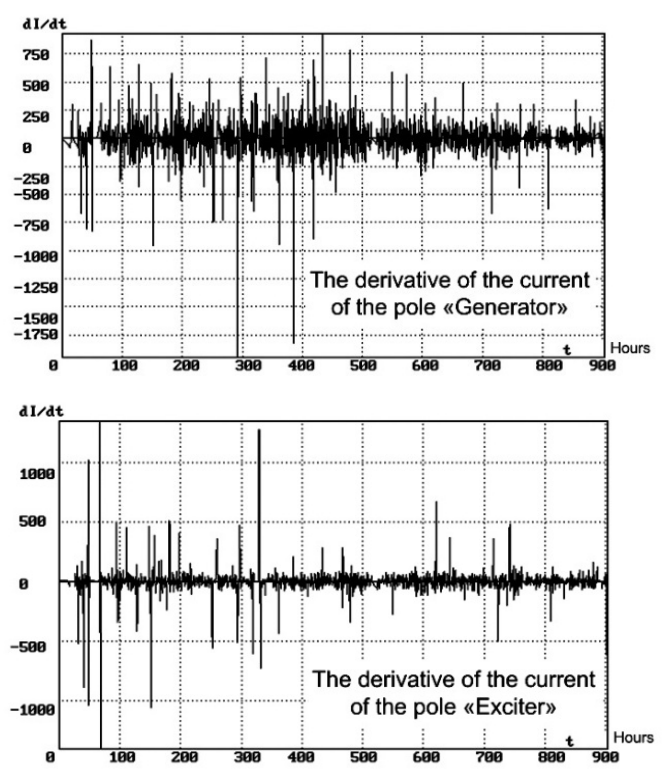

Fig. 11. The rate of BCD poles currents change of the turbogenerator TVV-800.

The assessment of dynamic asymmetries of the series of brushes load for the pole BCD is presented in a form of a phase trajectories (Fig. 12). The value of the total brushes current of the series $\mathrm{A}$ is postponed on the ordinate axis and of the series B on the abscissa axis.

Each phase contains two stochastic trajectories of the attractor, extending perpendicular to the bisector of the first quadrant. Therefore, a main displacement of the imaging point in the phase plane is caused by the processes of a redistribution of the current between the series. The number of attractors indicates two quasistatic modes with different values of the total load current. Moving along the bisectors are determined by fluctuations of the excitation current of the turbo-generator. The smaller current load of BCD at night can explain the existence of the small attractor.

Define the statistical distribution of the density of a realizations of a random process in the region of possible values of $\mathrm{p}\left(\mathrm{y} \in\left[\mathrm{y}_{\mathrm{s}}, \mathrm{y}_{(\mathrm{s}+1)}\right]\right)$. To build this graph we find the relative frequency of a random variable fall in the given intervals of values as a percentage of the total number of realizations. An example of probability density function for graphs of the cassettes currents and poles of BCD is shown in Fig. 13. The presence of two or more peaks indicate a long work in several quasi-stationary modes. The third part of the total number of cassettes relates to the latter category.
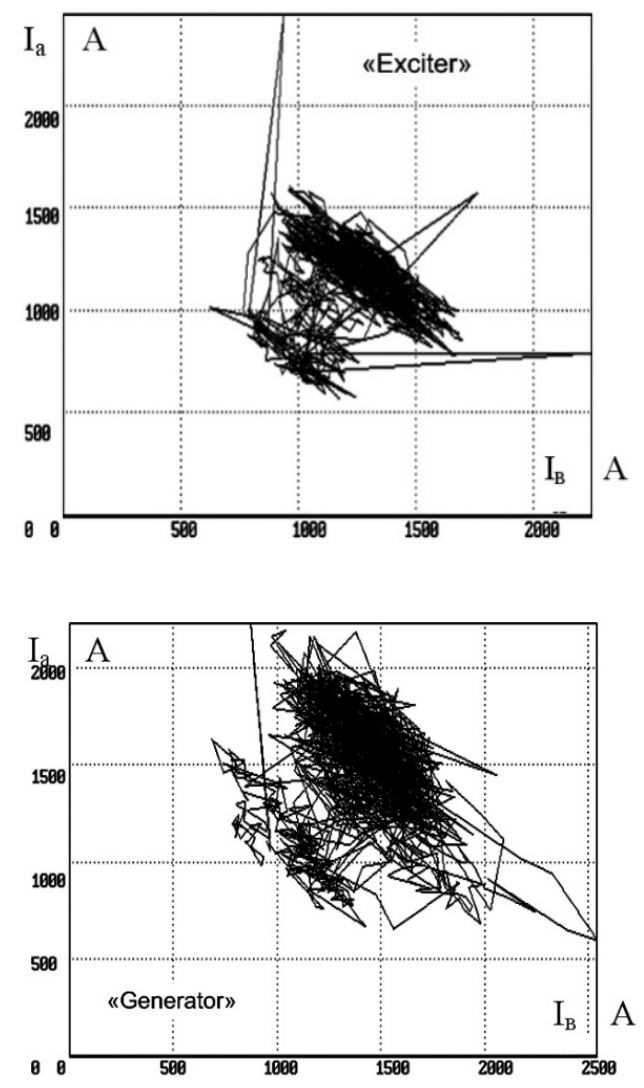

Fig. 12. The phase trajectory of current download of the series of brushes.

Let's show that for the monitoring system of current distribution of BCD main technical effect is to improve the quality of the current's distribution and the associated increasing of operation reliability of BCD.

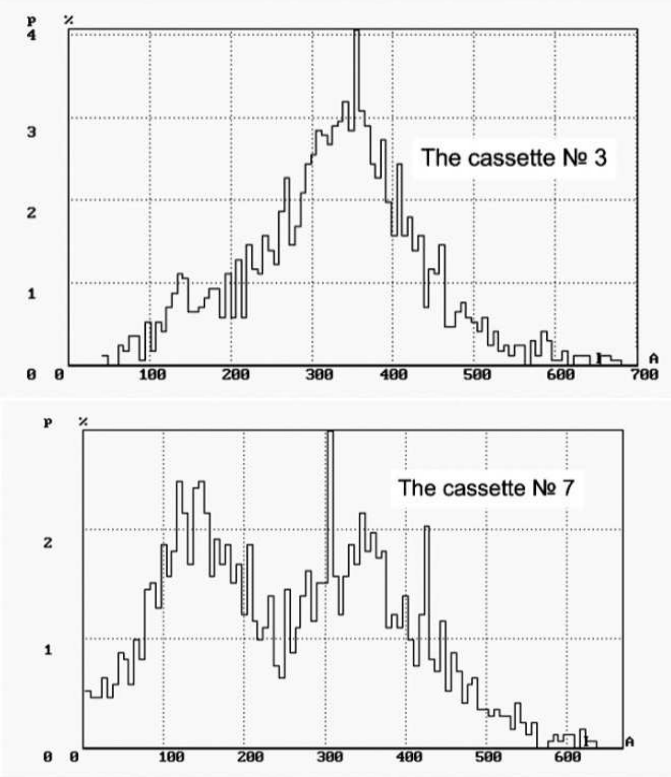



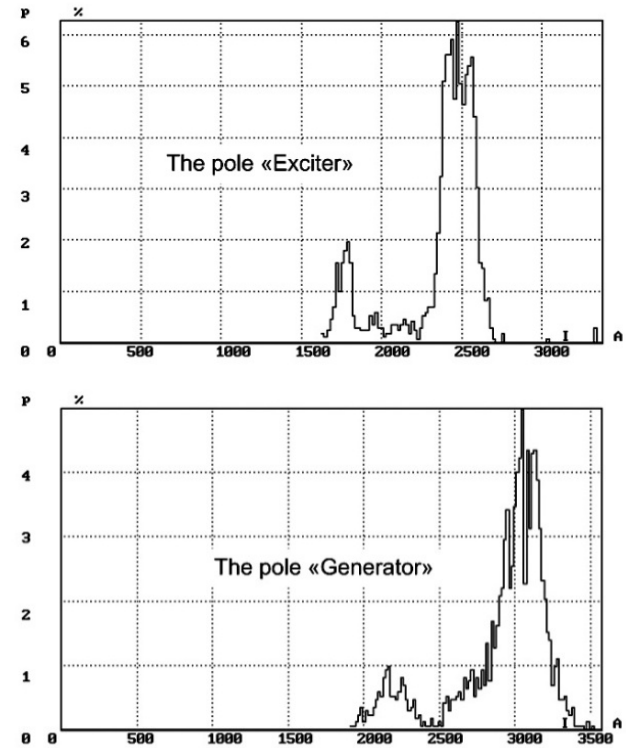

Fig. 13. The probability distribution of the currents of the cassettes and poles.

Let's show how the quality indicator of the current distribution Q (2) was changed in the search period. Its dependence on time for the poles is shown in Fig. 14. In the absence of the continuous monitoring and control of the technical condition of the indicator usually deteriorates as evidenced by the earlier experiments on the measurement of currents by the devices of on-line diagnostics.
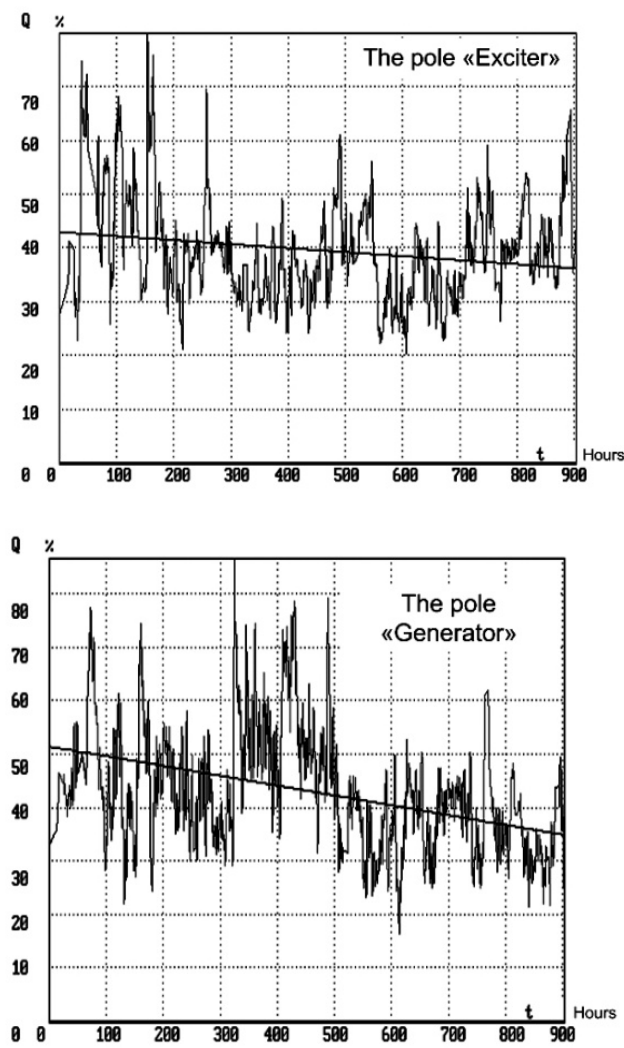

Fig. 14. The change of the indicator of the quality of current distribution during the study period (straight line - linear approximation of the obtained graph).
The diagrams show that the quality indicator of current distribution has improved in the process of the system working. Such conclusion allows to make an approximation by linearization of the graphs by the least square method. Moreover Q for pole " $E$ " dropped from 44 to $35 \%$ and was on average $9 \%$, and for the pole of "G" - from 52 to $35 \%$ and was $17 \%$. The relative drop reached $20 \%$ and $33 \%$ respectively. The steady-state value of the indicator in both cases reaches $35 \%$ although the initial levels differed significantly $(\mathrm{Q}=35 \%$ corresponds to an excellent expert evaluation for the even current distribution).

The positive effect after the tuning of the BCD current distribution on the readings of the monitoring system is resulted in the reduction of the dispersion of current series, poles and dispersion quality indicator (Fig. 15-17). The estimate of the variance was produced by calculating the standard deviation $\mathrm{W}$ by scanning processes with an interval of $5 \%$ of the analyzed time period. The decrease of the root-meansquare scattering is tens of percent in all cases.
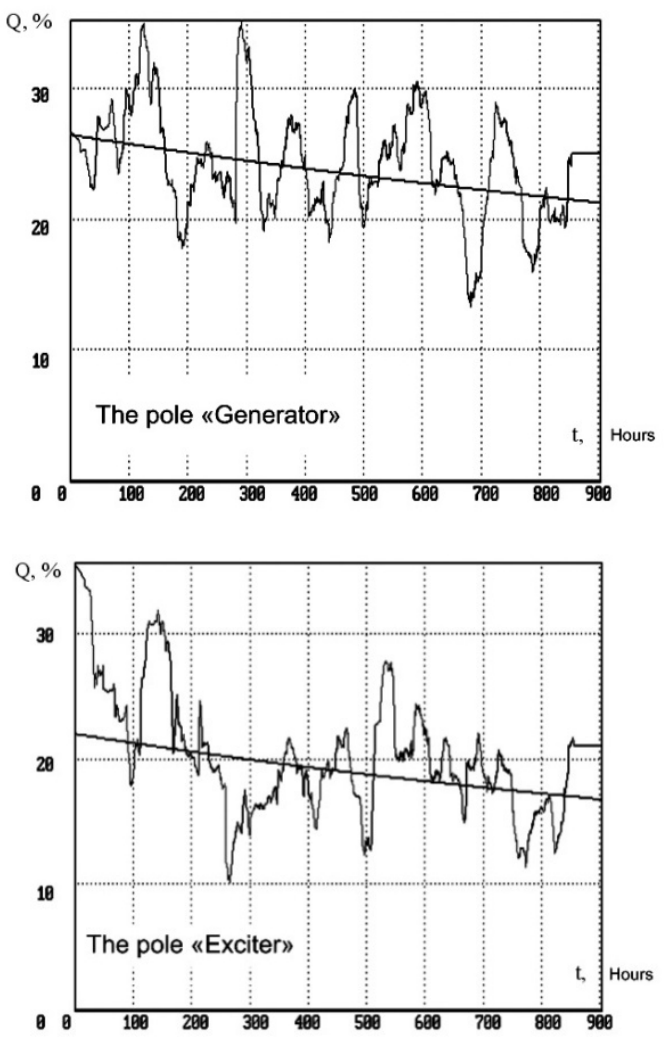

Fig. 15. The change of standard deviation of indicator of the quality of current distribution (straight line - linear approximation of the obtained graph). 
Environment. Technology. Resources, Rezekne, Latvia Proceedings of the $11^{\text {th }}$ International Scientific and Practical Conference. Volume III, 258-268
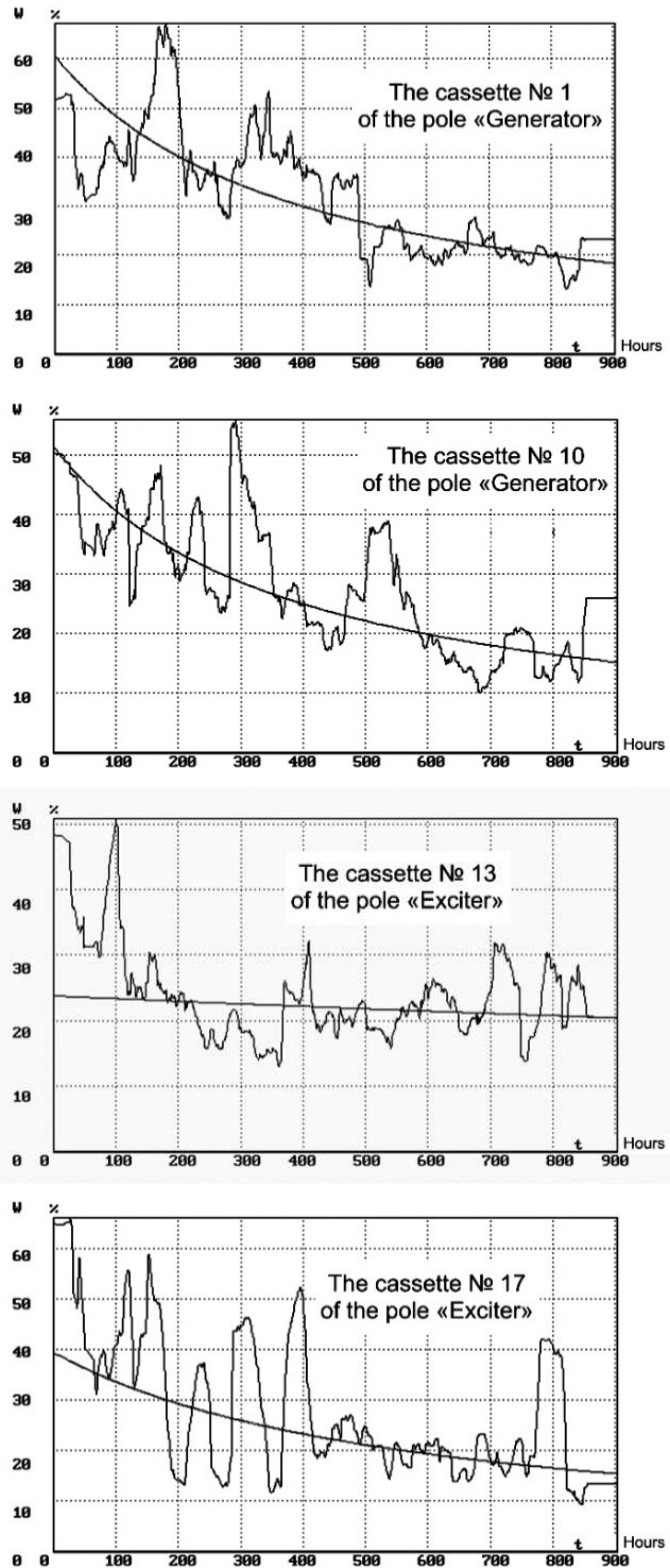

Fig. 16. The change of the standard deviation of the currents of the cassettes during the test period (drooping characteristic is nonlinear approximation of the obtained graph)/

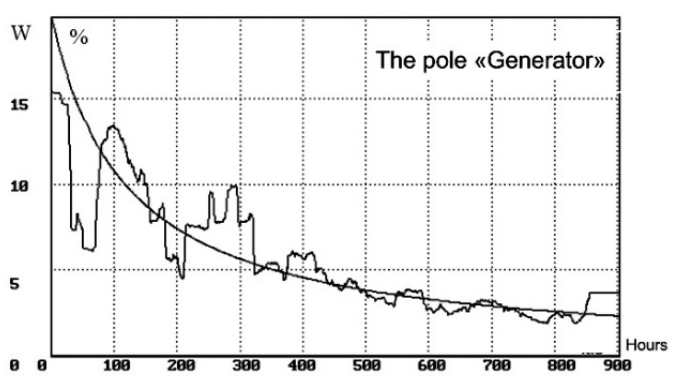

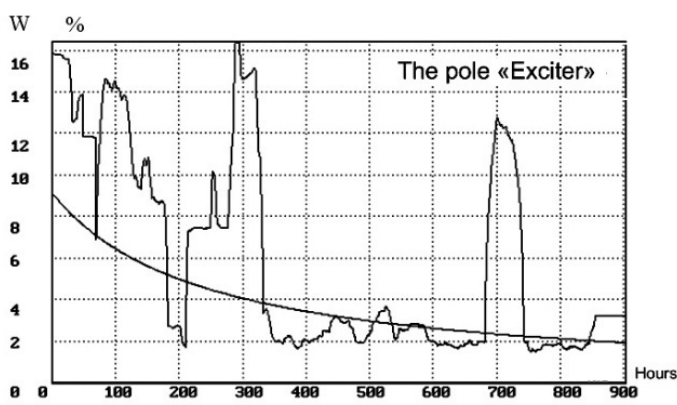

Fig. 17. The change of the standard deviation of the currents of the poles during the test period (drooping characteristic is nonlinear approximation of the obtained graph).

The data of the phase trajectory in the analyzed period of the work of BCD are shown in Fig. 18.
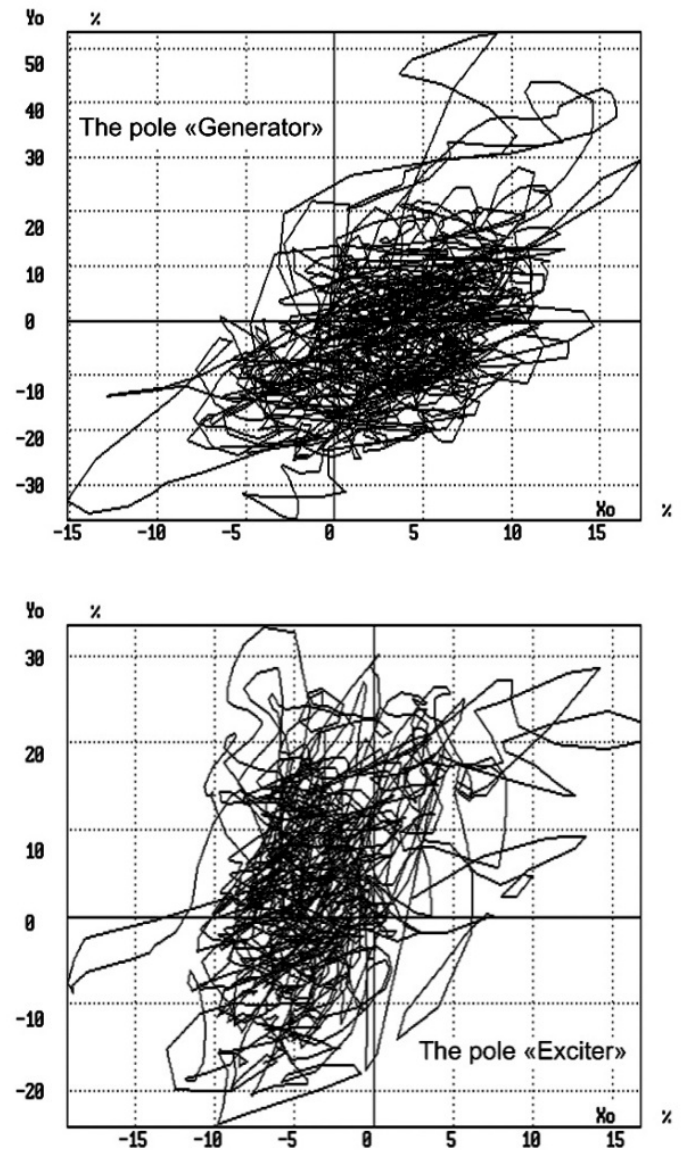

Fig. 18. Hodographs of the equilibrium of the currents of the poles of BCD of TVV-800.

The statistical average, the variance and the characteristic features of the configuration of the attractors are estimated from the given characteristics:

1) the statistically average coordinates of the points of the equilibrium: $\mathrm{X}_{0 \mathrm{G}}=-3.3 \%, \mathrm{y}_{\mathrm{OG}}=4.6 \%$ (pole "G") and $\mathrm{X}_{\mathrm{OE}}=3.5 \%, \mathrm{Y}_{\mathrm{OE}}=-1.5 \%$ (pole "E");

2) the process of moving the point of the equilibrium has a stochastic nature;

3) the fluctuations of a given point along the yaxis is about two times larger than along the $\mathrm{x}$-axis therefore the current is distributed less evenly in the 
vertical section of $\mathrm{BCD}$ due to the uneven influence of the gravity force on the different cassettes;

4) the attractor of the pole " $G$ " is stretched along the bisectrix of the 1-3 quadrants suggesting more active redistribution of the current between the cassettes 1-3 and 6-8, it allows to make a conclusion about the high instability of the current transfer through this cassettes;

5) the variance of the attractor pole " $G$ " is almost two times higher than the variance of the attractor " $E$ ", indicating a more stable process current transfer on the pole "E".
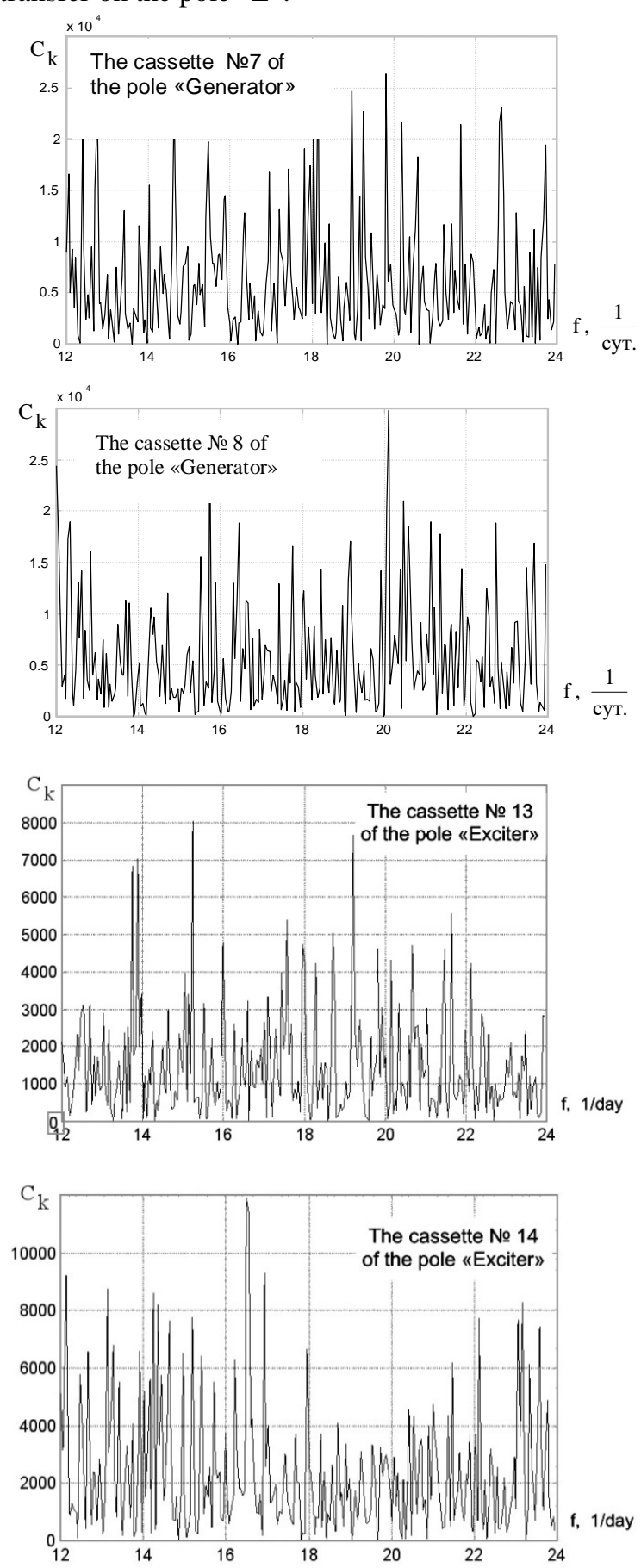

Fig. 19. Spectra of dynamic processes of transfer current through brush cassette (selective)
Let's consider the spectra of the analyzed processes obtained with a fast algorithm for the discrete Fourier transform in MATLAB (Fig. 19). We introduce for the spectral functions a marking of the frequency in units of $\left[\mathrm{Hz}^{*}\right]=\left[\mathrm{day}^{-1}\right]$.

A noticeable increase of amplitude is observed with the decrease of frequency especially in the region below $12 \mathrm{~Hz}^{*}$. The daily fluctuations of the currents have the highest levels. Additionally, the amplitude of the spectral components is much higher for pole " $G$ ", that indicates its unstable operation.

\section{CONCLUSION}

The presented new diagnostic system underwent industrial tests and proved its effectiveness in determining parameters of the current distribution in the BCD of the turbo-generator of Nizhnevartovsk State District Power Stations.

The developed new ways of assessing the quality of the BCD operation allowed us to evaluate the current transfer processes in static and dynamic modes and determine their qualitative characteristics.

During the operation of the diagnostic system new regularities of the current distribution in dynamic between brush cassette were discovered, which based on statistical and dispersion analysis allowed to develop practical recommendations for the maintenance of these units (replacement of brush cassettes, grinding of the rings, adjusting the force of pressing the brushes to the ring and etc.).

The new dynamic characteristics of the current distribution in the BCD developed by the authors include:

- vector diagram allowing to determine the unevenness of loading rows of brushes (vector of unbalance of series);

- the locus diagram of a equilibrium of the currents system of the pole of BCD.

- the locus diagram of a unbalance of current load of the sides of the pole of BCD

Upon review of the characteristics of the dynamic processes of the current transfer can make the following conclusions about the effectiveness of monitoring the current distribution of $\mathrm{BCD}$ of turbogenerator:

1) the monitoring system of the current distribution introduce a fairly strong negative feedback on the quality of functioning of manmachine systems of "BCD -technical staff";

2) the operation of diagnostic system improves the quality of the current distribution and reduces the dispersion processes of current transfer;

3) application of monitoring system the current distribution system simplifies the adjustment procedures, render possible promptly and reasonably to respond to adverse changes in the modes (for example sparking of individual brushes) and take targeted measures for maintenance, increases 
Environment. Technology. Resources, Rezekne, Latvia Proceedings of the $11^{\text {th }}$ International Scientific and Practical Conference. Volume III, 258-268

operating reliability of the current collector of the turbo-generator.

\section{V.ACKNOWLEDGMENTS}

This research was undertaken with the support of the management and staff of the electrical Department of the Nizhnevartovsk State District Power Stations.

Senior lecturer of Department of electric drive and automation systems PskovSU A. Andrusich have done extensive work on the development of a monitoring system.

The authors of the article congratulate prof. of Pskov State University I.V.Plokhov with the medal "For merits in the development of engineering education in Russia".

\section{REFERENCES}

[1] Хольм Р., Электрические контакты, М.: Иностранная литература, 1961.

[2] Кончиц В.В., Мешков В.В., Мышкин В.В. Триботехника электрических контактов, Минск: Наука и техника, 1986.

[3] O. I. Kozyreva, I. V. Plokhov, Y. N. Guraviev, I. E. Savraev, A. V. Ilyin, The regions of parametric instability of brushcontact device electromagnetic circuit in unstable working conditions Environment. Technology. Resources. Proceedings of the International Scientific and Practical Conference / Rezekne, REZEKNE HIGHER EDUCATION INSTITUTION. 2015 - Volume 1. P. 84-88.

[4] Method of Decreasing Arcing in Brush-Slip Ring Unit of Turbo-generators / Kozyreva O. I., Plokhov I.V., Ilyin A. V.,
// Proceedings of Tula State University. Engineering Sciences. 2012 \#12-2. P. 342-348.

[5] Henao H., Capolino G.A., Fernandez-Cabanas M., Filippetti F., Bruzzese C., Strangas E., Pucsa R., Riera-Guasp M., Hedayati-Kia S., Trends in Fault Diagnosis for Electrical Machines: A review of Diagnostic Techniques, IEEE industrial electronics magazine, vol. 8, No.2, June 2014. pp. 31-42.

[6] Toliyat, A., Nandi S., Choi S., Meshgin-Kelm H. Electric machines. Modeling, condition monitoring and fault diagnosis, CRC Press and Taylor \& Francis Group, edition 2012, $272 \mathrm{p}$.

[7] Juergen Klaar. Apparatus for monitoring a sliding contact element in an electrical rotating machine, US 20030011388 A1. 16.01.2003.

[8] Харламов В. В., Методы и средства диагностирования технического состояния коллекторно-щеточного узла тяговых электродвигателей $и$ других коллекторных машин постоянного тока: монография / В. В. Харламов. - Омск: ОмГУПС, 2002. - 233 с.

[9] Попов И.Н., Попов И.И, Попов Н.И., Способ измерения тока щеток шеточно-контактного аппарата синхронных генераторов, Патент на изобретение RU 2383029, опубликовано: 27.02.2010, бюл. № 6.

[10] Попов И.Н., Зражевский С.М., Калмыков А.В., Устройство для контроля токораспределения щеточноконтактного аппарата электрической машины, Патент на изобретение 2157033, опубликовано: 27.09.2000, бюл. № 27.

[11] Плохов И.В., Савраев И.Е., Андрусич А.В., Способ контроля токораспределения по комплектам щеток узла токосъема электрической машины и устройство для его осуществления, Патент на изобретение №2178609, опубликовано 20.01.2002.

[12] Плохов И.В., Савраев И.Е., Андрусич А.В., Диагностическая система для узлов токосъема турбогенераторов, Электросила № 40, 2001. 